\title{
A comparative clinical study of the failure rate of orthodontic brackets bonded with two adhesive systems: Conventional and Self-Etching Primer (SEP)
}

\author{
Gladys Cristina Dominguez¹, André Tortamano², Luiz Vicente de Moura Lopes³, \\ Priscilla Campanatti Chibebe Catharino ${ }^{4}$, Camillo Morea $^{5}$
}

\begin{abstract}
Objective: This study compared the clinical performance of orthodontic brackets bonded with Transbond adhesive paste after two priming systems: a two-stage conventional system (acid etching + Transbond XT adhesive primer) and a singlestage self-etching primer (SEP) (Transbond Plus). Methods: The sample comprised 480 metal brackets bonded to the teeth of 24 consecutive patients treated for 36 to 48 months. A split-mouth design was used for bonding, and both systems were used in each patient. Bracket failure rates for each system were analyzed; and failure causes as reported by the patients and the quadrant of teeth for which brackets failed were recorded. Results: The conventional system group had a failure rate of $5.41 \%$, whereas the rate for SEP was $4.58 \%$. In this group, there were 5 failures $(38.4 \%)$ in the right maxillary quadrant, $2(15.4 \%)$ in the left maxillary quadrant, $4(30.8 \%)$ in the right mandibular quadrant, and $2(15.4 \%)$ in the left mandibular quadrant. In the SEP group, there were 4 (36.4\%) failures in the right maxillary quadrant, 1 (9\%) in the left maxillary quadrant, $3(27.3 \%)$ in the right mandibular quadrant, and $3(27.3 \%)$ in the left mandibular quadrant. Results of descriptive statistical analysis and odds ratio did not show any significant differences between rates $(p=0.67)$. Conclusion: The clinical efficiency of SEP was similar to that of the conventional system.
\end{abstract}

Keywords: Orthodontic brackets. Bonding. Dental adhesive.

Objetivo: o objetivo do presente estudo foi comparar o desempenho clínico da colagem de braquetes ortodônticos com resina Transbond (3M Unitek) associada a dois sistemas adesivos: convencional em duas etapas (ataque ácido + Transbond XT adhesive Primer) e Self-Etching Primer (SEP), em etapa única (Transbond Plus). Métodos: a amostra foi constituída de 480 braquetes metálicos (Victory, 3M Unitek), colados em 24 pacientes, que foram tratados durante um período de 36 a 48 meses. A colagem foi feita por meio do sistema split-mouth, utilizando os dois sistemas de colagem em cada paciente. Foi analisada a taxa de queda dos braquetes para cada sistema de colagem, descrita a causa da queda conforme relato do paciente e a posição dos dentes nas arcadas. Resultados: o sistema adesivo convencional apresentou taxa de queda de 5,41\%, enquanto a do SEP foi de 4,58\%. O sistema convencional apresentou 5 quedas $(38,4 \%)$ no quadrante superior direito, $2(15,4 \%)$ no quadrante superior esquerdo, $4(30,8 \%)$ no quadrante inferior direito e $2(15,4 \%)$ no quadrante inferior esquerdo. O SEP apresentou 4 quedas $(36,4 \%)$ no quadrante superior direito, 1 (9\%) no quadrante superior esquerdo, $3(27,3 \%)$ no quadrante inferior direito e $3(27,3 \%)$ no quadrante inferior esquerdo. Por meio da análise estatística descritiva e do teste Odds Ratio, constatou-se que não houve diferença significativa entre essas taxas $(p=0,67)$. Conclusão: com base nesses resultados, pode-se concluir que o sistema adesivo SEP apresentou eficácia clínica semelhante à do sistema adesivo convencional.

Palavras-chave: Braquetes ortodônticos. Colagem dentária. Adesivos dentinários.

${ }^{1}$ Associate Professor, Department of Orthodontics and Pediatric Dentistry, School of Dentistry, São Paulo University (FOUSP), São Paulo, Brazil.

${ }^{2}$ Professor, PhD, Department of Orthodontics and Pediatric Dentistry, FOUSP, São Paulo, Brazil.

${ }^{3} \mathrm{PhD}$ student, Department of Orthodontics, FOUSP, São Paulo, Brazil. ${ }^{4}$ MSc student, Department of Orthodontics, FOUSP, São Paulo, Brazil.

${ }^{5}$ Post-doctor in Orthodontics, USP.

" The author reports no commercial, proprietary or financial interest in the products or companies described in this article.
How to cite this article: Dominguez GC, Tortamano A, Lopes LVM, Catharino PCC, Morea C. A comparative clinical study of the failure rate of orthodontic brackets bonded with two adhesive systems: Conventional and Self-Etching Primer (SEP). Dental Press J Orthod. 2013 Mar-Apr;18(2):55-60.

Submitted: August 26, 2010 - Revised and accepted: April 11, 2011

Contact address: Luiz Vicente de Moura Lopes

Av. Prof. Lineu Prestes, 2227 - Cidade Universitária - São Paulo/SP, Brazil CEP: 05.508-000 - E-mail: luizvicentelopes@me.com 


\section{INTRODUCTION}

The sixth generation of adhesive systems, called self-etching primers (SEP), reduced the number of bonding stages because it eliminated the need to apply phosphoric acid and, consequently, reduced clinical time and the risk of contamination. However, Transbond Plus SEP (3M Unitek, Monrovia, CA) has a more conservative pattern and produces a smaller amount of demineralization and less penetration into the enamel surface than phosphoric acid (37\%). ${ }^{1}$

Dominguez-Rodriguez et al conducted a series of studies from 2002 to 2004 to evaluate the reliability of this SEP system. In an in vitro study to evaluate resistance to traction, ${ }^{2}$ brackets were bonded to human premolars extracted for orthodontic reasons. Mean resistance to traction was $6.25 \pm 1.61 \mathrm{MPa}$, practically the same optimal values recommended in the literature ${ }^{3,4}(6 \mathrm{MPa})$. Their next in vitro study of bonding to extracted human premolars compared SEP resistance to traction with that of a conventional system using Victory (3M Unitek, Monrovia, CA) metal brackets and the adhesive pre-coated (APC) system. ${ }^{5}$ Mean values were $8.1 \pm 2.7 \mathrm{MPa}$ in the SEP group, and $10.3 \pm 3.2 \mathrm{MPa}$ for the conventional system, similar to those found by Grubisa et $\mathrm{al}^{6}$ in another comparative study: $7.7 \pm 4.2 \mathrm{MPa}$ for SEP and $9.8 \pm 4.2 \mathrm{MPa}$ for the conventional system.

These findings suggested that the clinical applicability of SEP should be confirmed in clinical trials. A study to measure the frequency of metal bracket failure during orthodontic treatment included 278 teeth of 17 patients. $^{7}$ All brackets were bonded using a SEP system. Patients were followed up for 30 months, and results showed a bracket failure rate of $5.8 \%$ for all the teeth included in the analysis. Failure causes were associated with excessive application of force and with biting food that should have been excluded from regular diet according to initial instructions, such as candy and lollypops.

Reis et al, ${ }^{8}$ who followed up 30 patients for 18 months, found a failure rate of $15.6 \%$ for SEP and $17.6 \%$ for the conventional system, a difference that was not statistically significant. Pandis et $\mathrm{al}^{9}$ conducted a study to compare SEP with the Orthosolo and Enlight conventional systems in 62 patients for 12 months and found that the risk of failure in the SEP group was not any greater than in the conventional system group.
Elekdag-Turk et al, ${ }^{10}$ in 2008, compared failure rates between SEP and the conventional adhesive systems. They followed up patients for 6 months and reported that there were no significant differences between the adhesive systems under study and that both had a failure rate of $0.6 \%$. In another study, the same authors ${ }^{11}$ compared the failure rates of selfligating brackets bonded with either SEP or a conventional adhesive system. They followed up patients for 12 months and reported that there was a significant difference between the two systems, as the SEP group had a rate of $4.7 \%$, whereas the rate for the conventional system was $1.7 \%$.

Santos et $\mathrm{al}^{12}$ conducted a study with a 6 -month follow-up; they found that failures were associated with the adhesive-enamel interface, and that failure rates for SEP and the conventional system were $10.6 \%$ and $7.4 \%$. In the same way, Murfitt et a ${ }^{13}$ recorded bracket failure rates for 12 months and found a significantly greater rate for teeth to which brackets had been bonded with SEP (11.2\%) rather than the conventional adhesive system (3.9\%).

In a recent study, Paschos et a ${ }^{14}$ compared different SEP adhesive systems: Transbond Plus (3M Unitek, Germany) and Clearfil Protect Bond (Kuraray Medical, Japan). They included 480 brackets in their study and, after a 12-month follow-up, found a failure rate of $5.4 \%$ (26 brackets), which was significantly greater than that found for brackets bonded with Clearfil Protect Bond (4.4\%).

This clinical study used the split-mouth bonding design to evaluate bracket failure rates in individuals that underwent full orthodontic treatment for 36 to 48 months using the conventional system with acid etching (37\% phosphoric acid) together with the Transbond XT adhesive (3M Unitek, Monrovia, CA) and the Transbond Plus SEP (3M Unitek, Monrovia, CA).

\section{MATERIAL AND METHODS}

The sample comprised 480 metal brackets (Victory) bonded to the teeth of 24 consecutive patients that were treated in the MBT Orthodontic Treatment Clinic of São Paulo University. No patient had received previous orthodontic treatment. After diagnosis and treatment plan, patients were treated with extraction of the four first premolars. 
The split-mouth design was used for bracket bonding, and was divided into groups randomly. Patient dentition was divided into four quadrants, and one adhesive system was used in the right maxillary and left mandibular quadrants, and the other, in the left maxillary and right mandibular quadrants. In one group, 240 teeth underwent etching and priming using the two-stage conventional method: Acid etching with $37 \%$ phosphoric acid and bonding with Transbond XT adhesive paste. The other 240 teeth were primed using the Transbond Plus SEP (3M Unitek, Monrovia, CA). After that, all brackets were bonded using the Transbond XT resin.

The same bracket bonding protocol was strictly followed for each patient. First, prophylaxis was performed with rubber cup, pumice and water spray using a low-speed handpiece, and then teeth were rinsed with water. The place where to bond the brackets was defined according to the tables of the MBT treatment system and marked with a lead pencil on the buccal surface of the teeth. After that, the field was isolated using cheek retractors, and the actual process of bonding the brackets started.

In the quadrants chosen for the Transbond Plus SEP system, application followed the manufacturer's instructions: 1) contents of the first two reservoirs were squeezed into the third; 2) a micro brush was used to mix and apply the liquid to the enamel surface in circular movements while applying some pressure for three seconds; 3) excessive liquid was removed with a gentle air burst to leave a thinner liquid layer on the enamel. After that, direct bonding was performed. A thin layer of Transbond XT resin was applied to the base of each bracket. After removing excess resin, a halogen light was used for curing for 40 seconds (10 s for each surface).

In the contralateral quadrants chosen for conventional bonding, the field was isolated, teeth underwent acid etching (37\% phosphoric acid; Dentsply) for 20 seconds, rinsing for 5 seconds per tooth, and drying for 10 seconds. A thin layer of Transbond XT adhesive primer was then applied to the surface of the tooth using a micro brush. The procedures to dispense resin onto the bracket base and directly bond the brackets were the same as those for bonding in the contralateral quadrant, which used the SEP system.

The leveling phase started on the same day. Patients received routine instructions about appliance cleaning and care, particularly about foods and habits that may damage the appliance.

Bracket failures were controlled and their causes and corresponding tooth were recorded during all treatments, which ranged from 36 to 48 months.

\section{Statistical analysis}

Descriptive statistics was used to analyze the number of bracket failures per individual, what bonding system was used in maxilla and mandible, failure causes and their percentages, and mean time between bonding and failure in months. The values obtained for bracket failure were compared (odds ratio $-0.839 ; \mathrm{p}=0.676$ ).

\section{RESULTS}

The results are presented in Table 1 to 5 .

\section{DISCUSSION}

Bracket failure rates were compared for the conventional and the SEP bonding systems. Orthodontic treatments with extraction of the maxillary and mandibular first premolars in 24 consecutive patients were evaluated during the different treatment phases: Leveling, alignment, space closure and finishing. Several factors were taken into consideration: Whether the tooth was in the maxilla or mandible; the quadrant (right and left); the type of tooth (incisor, canine, premolar and molar); failure causes; and mean time between bonding and failure.

Efficient bracket bonding and low failure rates are important factors in orthodontic treatments. As a complete orthodontic treatment may last from 24 to 48 months, bonding efficiency of the two systems under study was evaluated during all the treatments, which ranged from 36 to 48 months.

A split-mouth design for bonding was used to compare the two systems in each patient. This randomized method ensures that, of each 10 brackets bonded consecutively, 5 will be bonded using the conventional system in the maxillary right quadrant and 5 will use the SEP in the maxillary left quadrant. The same bonding system is used in contralateral quadrants so that, together with different bonding systems, analyses may include eating habits and individual mastication forces for each patient. ${ }^{12,13}$

Tables 1 and 2 show that the distribution of failure was similar in the maxilla and mandible for both 
Table 1 - Number of failures according to tooth and bonding system in the upper arch.

\begin{tabular}{ccccc}
\hline Tooth & \multicolumn{2}{c}{ Right quadrant } & \multicolumn{2}{c}{ Lefit quadrant } \\
& SEP & Conventional & SEP & Conventional \\
\hline Incisors & 0 & 2 & 0 & 0 \\
\hline Canines & 1 & 0 & 0 & 0 \\
\hline Premolars & 2 & 2 & 0 & 2 \\
\hline 2nd molars & 1 & 1 & 1 & 0 \\
\hline Total & 4 & 5 & 1 & 2 \\
\hline
\end{tabular}

Table 3 - Total number of bracket failures according to bonding system.

\begin{tabular}{|ccc}
\hline Quadrant & SEP & Conventional \\
\hline Right maxillary & 4 & 5 \\
\hline Left maxillary & 1 & 2 \\
\hline Right mandibular & 3 & 4 \\
\hline Left mandibular & 3 & 2 \\
\hline Total & 11 & 13 \\
\hline \% of failures & 4.58 & 5.41 \\
\hline
\end{tabular}

Table 2 - Number of failures according to tooth and bonding system in the lower arch.

\begin{tabular}{|c|c|c|c|c|}
\hline \multirow{2}{*}{ Tooth } & \multicolumn{2}{|c|}{ Right quadrant } & \multicolumn{2}{|c|}{ Left quadrant } \\
\hline & SEP & Conventional & SEP & Conventional \\
\hline Incisors & 0 & 2 & 0 & 0 \\
\hline Canines & 1 & 1 & 0 & 1 \\
\hline Premolars & 0 & 1 & 1 & 1 \\
\hline 2nd molars & 2 & 0 & 2 & 0 \\
\hline Total & 3 & 4 & 3 & 2 \\
\hline
\end{tabular}

Table 4 - Cause of bracket failure (number and percentage of failures).

\begin{tabular}{ccc}
\hline Failure cause & SEP & Conventional \\
\hline Biting candy & $3(27.3 \%)$ & $4(30.7 \%)$ \\
\hline Biting olive & $1(9 \%)$ & $1(7.7 \%)$ \\
\hline Trauma & $2(18.2 \%)$ & 0 \\
\hline Diet in general & $5(45.5 \%)$ & $8(61.6 \%)$ \\
\hline
\end{tabular}

Table 5 - Mean time between bonding and failure (months).

\begin{tabular}{|c|c|c|c|c|c|c|c|c|}
\hline \multirow{3}{*}{ Teeth } & \multicolumn{4}{|c|}{ Upper arch } & \multicolumn{4}{|c|}{ Lower arch } \\
\hline & \multicolumn{2}{|c|}{ Right quadrant } & \multicolumn{2}{|c|}{ Left quadrant } & \multicolumn{2}{|c|}{ Right quadrant } & \multicolumn{2}{|c|}{ Left quadrant } \\
\hline & SEP & Conventional & SEP & Conventional & SEP & Conventional & SEP & Conventional \\
\hline Incisors & 0 & 9.5 & 0 & 0 & 0 & 5 & 0 & 0 \\
\hline Canines & 1 & 0 & 0 & 0 & 24 & 2 & 0 & 6 \\
\hline Premolars & 1 & 1 & 0 & 2 & 0 & 2 & 36 & 2 \\
\hline 2nd molars & 3 & 1 & 11 & 0 & 1 & 0 & 1.5 & 0 \\
\hline
\end{tabular}

SEP (maxilla $=5$; mandible $=6$ ) and conventional $($ maxilla $=7 ;$ mandible $=6)$ systems. Studies in the literature, as well as this study, found a nonsignificant difference in bracket failure rates between the two arches. There were 12 failures in the maxilla and 12 in the mandible, which confirmed equal rates.

The comparison of right and left quadrants in the maxilla and in the mandible revealed that there were 16 failures in the right quadrant ( $\mathrm{SEP}=7$; conventional $=9)$ and 8 in the left quadrant $(\operatorname{SEP}=4$; conventional $=4$ ). One possible explanation for that might be the patients' masticatory habits. ${ }^{9}$ In vivo studies should take into consideration factors that might be associated with failure rates, such as patient socioeconomic status, malocclusion classification and type of mechanics used during treatment. Moreover, masticatory forces vary according to facial patterns, and diet is associated with cultural factors. ${ }^{8,11}$
The number of times the bracket is handled during bonding should also be evaluated in the analysis of bracket failures. Brackets handled more than three times when a SEP system is used have twice as many chances of failure than those bonded with a conventional bonding system. ${ }^{13}$

Several authors conducted shorter studies to compare SEP and conventional systems, from 6 to 12 or 18 months. ${ }^{8-14}$ Our follow-up lasted longer, from 36 to 48 months.

Some authors found that the failure rate for SEP ranged from $0.6 \% 10$ to $15.6 \%{ }^{8}$ and that the SEP performance was equal to or better than that of conventional systems. Of the 240 brackets bonded with each of the two bonding systems, 11 in the SEP group and 13 in the conventional system group failed, which indicates failure rates of $4.58 \%$ and $5.41 \%$ (Table 3 ). Odds ratio results showed that there were no signifi- 
cant differences between these values, in agreement with most reports in the literature, ${ }^{9,10,11,12}$ but different from studies that found greater failure rates for brackets bonded with SEP than for those bonded with conventional systems. ${ }^{13,15}$ The fact that numbers and percentages are very close suggests that both the SEP and the conventional systems are equally efficacious.

Most failures occurred in premolars, at 9 failures, followed by molars, with 7 , and the least failures were seen in incisors and canines, at 4 failures each (Tables 1 and 2). These findings are in agreement with studies that reported a three times greater rate for posterior teeth than for anterior teeth. ${ }^{11,13,16,17}$ The fact that premolars are the teeth with the highest rate may be explained as a result of several factors: Lower risk of contamination by humidity in the anterior region during bonding; occlusal forces that exceed the limits of adhesive resistance of the brackets; greater amount of prismless enamel, which may affect the quality of micromechanical bonding and result in poor adhesion; and the difficulty to isolate the posterior region. ${ }^{7}$

Mean time between bonding and bracket failure (Table 5) showed great variation and ranged from 1 to 36 months. Despite that, most failures occurred in the first 6 months of treatment, and only four means indicated longer times. Two of these four cases were assigned to the sum of one failure in the beginning of the treatment and one at the end of it. The other two high means rep- resented failures at the end of the treatment. The fact that most failures occurred in the first 6 months may be assigned to one of three causes. First, any problem during bonding becomes evident in the beginning of the treatment. Second, the initial period of the treatment is a time for adaptation of the patient to the diet. Finally, there may be excessive occlusal forces during the initial stage of treatment. ${ }^{8,11}$ Some authors have reported a failure rate of up to $82 \%$ during this time. ${ }^{10}$

Other studies confirmed the efficacy of SEP systems during the first 6 months of treatment when compared with conventional systems. ${ }^{8}$ After a longer treatment time, the difference between failure rates for the two bonding systems may become imperceptible. This is explained by the hydrophilic component of the monomer, which leads to increased water absorption and may weaken the adhesive-bracket interface along time. This was confirmed in our study, because mean time between bonding and bracket failure was greater when the SEP system was used (Table 5).

Regardless of time, failures were assigned to either patient diet in general, because patients did not follow initial diet recommendations, or to trauma (Table 4).

\section{CONCLUSIONS}

The efficacy of the SEP bonding system was similar to that of the conventional system, and its use in orthodontics seems to be reliable. 


\section{REFERENCES}

1. Cal-Neto JP, Miguel JA. Scanning electron microscopy evaluation of the bonding mechanism of a sel-etching primer on enamel. Angle Orthod. 2006:76(1):132-6

2. Dominguez-Rodriguez GC, Carvalho PAL, Horliana R, Bomfim RA, Vigortio, JW. Avaliação in vitro da resistência à tração de braquetes metálicos colados com o novo sistema adesivo self etching primer (SEP). Ortodontia. 2002:35(2):28-34

3. Reynolds IA. A review of direct orthodontic bonding. $\mathrm{Br} \mathrm{J}$ Orthod. $1975: 2(3): 171-8$

4. Whitlock BO, Eick JD, Ackerman RJ, Glaros AG, Chappell RP. Shear strength of ceramic brackets to porcelain. Am J Orthod Dentofacial Orthop. 1994;106(4):358-64

5. Dominguez-Rodriguez GC, Horliana R, Carvalho PAL, Vigorito JW Avaliação in vitro da resistência à tração de dois sistemas adesivos usados na colagem de braquetes metálicos com resina pré-incorporada à base. Ortodontia. 2003:36(3):8-14

6. Grubisa HS, Heo G, Raboud D, Glover KE, Major PW. An evaluation and comparison of orthodontic bracket bond strengths achieved with selfetching primer. Am J Orthod Dentofacial Ortop. 2004;126(2):213-9.

7. Dominguez GC, Tortamano A, Carvalho PAL, Bonfim RA, Horliana R Vigortio JW. Self-etching primer - resistência confiável na colagem de acessórios ortodônticos? Estudo clínico. Ortodontia. 2004;38(1):10-5

8. Reis A, Santos JE, Loguercio AD, Bauer JRO. Eighteen-month bracket survival rate: conventional versus self-etch adhesive. Eur J Orthod. 2008:30(1):94-9
9. Pandis N, Polychronopoulou A, Eliades T. Failure rate of self-ligating and edgewise brackets bonded with conventional acid etching and a selfetching primer. Angle Orthod. 2006;76(1):119-22.

10. Elekdag-Turk S, Isci D, Turk T, Cakmak F. Six-month bracket failure rate evaluation of self-etching primer. Eur J Orthod. 2008;30(2):211-6.

11. Elekdag-Turk S, Cakmak F, Isci D, Turk T. 12-month self-ligating bracket failure rate with a self-etching primer. Angle Orthod. 2008;78(6):1095100.

12. Santos JE, Quioca J, Loguercio AD, Reis A. Six-month bracket survival with self-etch adhesive. Angle Orthod. 2006;76(5):863-8.

13. Murfitt PG, Quick AN, Swain MV, Herbison GP. A randomized clinical trial to investigate bond failure rates using a self-etching primer. Eur J Orthod 2006:28(5):444-9.

14. Paschos E, Kurochkina N, Huth KC. Hansson CS, Rudzki-Janson I. Failure rate of brackets bonded with antimicrobial and fluoride-releasing, selfetching primer and the effect on prevention of enamel demineralization. Am J Orthod Dentofacial Orthop. 2009:135(5):613-20

15. Ireland $\mathrm{AJ}$, Knight $\mathrm{H}$, Sherrif $\mathrm{M}$. An in vivo investigation into bond failure rates with a new self-etching primer system. Am J Orthod Dentofacial Orthop. 2003:124(3):323-6.

16. Barry GRP. A clinical investigation of the effects of omission of pumice prophylaxis on band and bond failure. J Orthod. 1995:22(3):245-8

17. Sunn S, Rock W. Clinical performance of orthodontic brackets and adhesive system: a randomized clinical trial. J Orthod. 1998:25(4):283-7. 